[This is a pre-print of a peer-reviewed and accepted paper. This version of the manuscript is published in the journal Appetite.]

\title{
Going veggie: identifying and overcoming the social and psychological barriers to veganism
}

\author{
Christopher J. Bryant ${ }^{1 *}$, Annayah M.B. Prosser $^{1} \&$ Julie Barnett $^{1}$ \\ ${ }^{1}$ Department of Psychology, University of Bath, Claverton Down, Bath, BA2 7AY, United \\ Kingdom \\ *C.J.Bryant@bath.ac.uk
}

\begin{abstract}
We conceptualize the journey to ethical veganism in the stages of the transtheoretical model of change, from precontemplation through contemplation, preparation, action, and maintenance. At each stage, we explore the psychological barriers to progressing towards veganism, discuss how they manifest, and explore ways to overcome them. It is hoped that this paper can be used as a guide for animal advocates to identify the stage an individual is at, and understand and overcome the social and psychological barriers they may face to progressing. We argue that, while many people are ignorant of the cruel practices entailed in animal farming, many deliberately avoid thinking about the issue, are unable to appreciate the scale of the issue, and simply tend to favour the status quo. When engaging with the issue of farm animal suffering, meat-eaters are largely driven by cognitive dissonance, which manifests as motivated reasoning aimed at protecting one's image of oneself and one's society. This is facilitated by confirmation bias and complicit media which cater to the preferred views of their meat-eating audience. Even once convinced of veganism, habit and willpower present further barriers to acting on those beliefs. This is all in the context of a speciesist and carnistic culture where meat consumption is normal, farming is noble, and vegans are 'others'. We locate and elucidate each of these biases within the stages of the transtheoretical model and discuss the implications of this model for animal advocates and for further research.
\end{abstract}

Keywords: Cognitive bias, transtheoretical model, persuasion, consumer psychology, vegetarian, vegan 


\section{Introduction}

This paper is an exploration of the evidence for social and psychological barriers to meat reduction at each stage of the Transtheoretical Model of change, as well as possible ways to overcome them. In this section, we briefly make the case against animal product consumption before introducing the paper's theoretical framework for behaviour change.

\subsection{Eating animals}

Aside from the devastating effects of animal agriculture on public health and the environment (IPCC, 2018; Martin, Thottathil \& Newman, 2015; Poore \& Nemecek, 2018; Willett et al., 2019), the moral case against the animal suffering it entails is straightforward.

First, it is extremely likely that farmed animals are conscious and can suffer. Griffin and Speck (2004) found that the evidence strongly supports this view: (a) there are no known neural correlates of consciousness which are unique to humans, (b) animal responses to novel challenges suggest a versatility which implies conscious thinking, and (c) reports on animal communication show evidence for animals having subjective experiences. Indeed, there is virtual scientific consensus on animal consciousness, as laid out in the Cambridge Declaration on Consciousness (Low et al., 2012).

Second, buying animal products directly funds the imprisonment, mutilation, and slaughter of animals - all of these things are entailed in the industrial production of milk and eggs, as well as meat (Joy, 2011). Third, it is perfectly possible for the vast majority of Western consumers to live healthily without consuming animal products - in fact, reducing animal product consumption would benefit most such peoples' health (Melina, Craig \& Levin, 2016; Willett et al., 2019). Clearly, industrial animal agriculture inflicts extreme suffering on conscious animals. Despite perceived nutritional benefits, when one considers the catalytic effect of animal farming on climate change, antibiotic resistance, and pandemics, one might reasonably conclude that it represents a net negative for humans as well. Industrial animal agriculture causes unnecessary suffering, and can reasonably be called immoral.

Indeed, this is a practice that most people, including those who purchase the products of animal agriculture, view as morally dubious: $70 \%$ of Americans have some level of discomfort when thinking about what happens to animals in the food system (Reese, 2017). Despite this, the vast majority of people also financially support factory farming every day (Ipsos, 2016). Researchers have dubbed this the 'meat paradox' - people both love animals, and pay for their slaughter (Loughnan, Bastian \& Haslan, 2010). While some people choose not to support industrial animal agriculture, the vast majority of people still consume animal products (Ipsos, 2016).

It is clear that individuals differ in their propensity to reduce their meat consumption - whilst some are simply ignorant of the case for meat reduction, others resist the arguments, and 
others still acknowledge the case without taking significant action. Therefore, a framework to conceptualise individuals' journeys towards veganism is necessary.

\subsection{The Transtheoretical Model}

This paper adopts the transtheoretical model (TTM) as a framework for conceptualizing the different stages of a transition towards veganism, and discusses the social and psychological barriers to progressing through the stages. We hope that this will provide a useful guide to educate advocates, policy-makers and marketers on how to best interact with meat-reducers at various stages of their journey to veganism for long-lasting change.

The TTM (also known as the stages of change model) is often applied to behaviour change in health research, in particular for breaking addictions (Prochaska \& DiClemente, 1983; Prochaska \& Velicer,1997). The TTM has been applied to what are termed 'problematic behaviours' such as smoking, drug abuse, and in recent years, meat consumption (Mendes, 2013; Salehi, Diaz \& Redondo, 2020).

The TTM model comprises three major components, summarised in Table 1 below. First, the six stages of change denote different periods in an individual's behaviour change journey: from precontemplation (i.e. before any awareness of the need to change) contemplation of changing, preparation to change, taking action, maintaining the change, and finally termination (long-term adoption of a new behaviour). Theorists note that the model does not imply that everyone will progress through every stage, and individuals may relapse, moving back to earlier stages (Prochaska \& Velicer. 1997).

Second, the ten processes of change denote common thought patterns which occur as a person moves through the stages of change. These include consciousness raising (becoming aware of the problem) and dramatic relief (negative emotions associated with the behaviour) in the early stages. Next, self- and environmental-reevaluation occurs as people decide to change (realizing the impact of the behaviour on themselves and others). As people change the behaviour, they may experience self- and social-liberation (seeing themselves differently and society generally being supportive of positive change). Finally, as the person moves to the maintenance stage, they may use counter-conditioning (adopting replacement habits), helping relationships (supportive people who encourage the change), reinforcement management (rewarding positive behaviours and not negative ones) and stimulus control (removing reminders or cues of the negative behaviour).

Third, a person's success in changing their behaviour is largely contingent on two factors: the decisional balance (i.e. a person's evaluation of the pros and cons of changing) and the person's self-efficacy (i.e. their ability to control their behaviour and avoid temptation (Prochaska \& Velicer, 1997). 
Table 1: The transtheoretical model.

\begin{tabular}{|c|c|c|}
\hline Stages of change & Processes of change & Determining components \\
\hline Pre-contemplation & $\begin{array}{l}\text { Consciousness raising } \\
\text { Dramatic relief }\end{array}$ & \multirow{6}{*}{$\begin{array}{l}\text { Decisional balance } \\
\text { Self-efficacy }\end{array}$} \\
\hline Contemplation & $\begin{array}{c}\text { Self-re-evaluation } \\
\text { Environmental re-evaluation }\end{array}$ & \\
\hline Preparation & Self liberation & \\
\hline Action & Social liberation & \\
\hline Maintenance & \multirow{2}{*}{$\begin{array}{c}\text { Helping relationships } \\
\text { Counterconditioning } \\
\text { Reinforcement management } \\
\text { Stimulus control }\end{array}$} & \\
\hline Termination & & \\
\hline
\end{tabular}

Mendes (2013) gives an excellent overview of how the various components of the stages of change model relate to veganism. She outlines (1) the behaviours people may exhibit at each stage from precontemplation to termination, (2) how some processes of change are relevant at different stages, and (3) some components related to the decisional balance and self efficacy. Here, we seek to build on Mendes' work by integrating empirical evidence of known psychological phenomena relevant to the transtheoretical model vis-à-vis veganism.

Several longitudinal studies of meat reduction utilize similar frameworks. In particular, Klöckner and Ofstad (2017) profiled participants according to the Model of Action Phases (MAP). The MAP is similar to the TTM, although it consists of fewer stages, classifying individuals as simply at the stage of pre-decision, decision, pre-action, or post-action. The authors found that those who were exposed to interventions matched to their stage of the MAP reduced their beef consumption significantly more than those who were exposed to unmatched interventions or a control. This work demonstrates that understanding a person's stage of action, and the discrete difficulties people at each stage may face is vital for meatreducing advocates to effect change.

More recently, Salehi, Diaz and Redondo (2020) expanded the stages of change model in the context of veganism to include the Precaution Adoption Process Model (PAPM), which adds two intermediate stages to TTM to allow for the possibility of disengagement or failure to change the behaviour (see Figure 1). 
Figure 1: The adapted TTM of adopting a vegan diet (Salehi, Diaz \& Redondo, 2020).

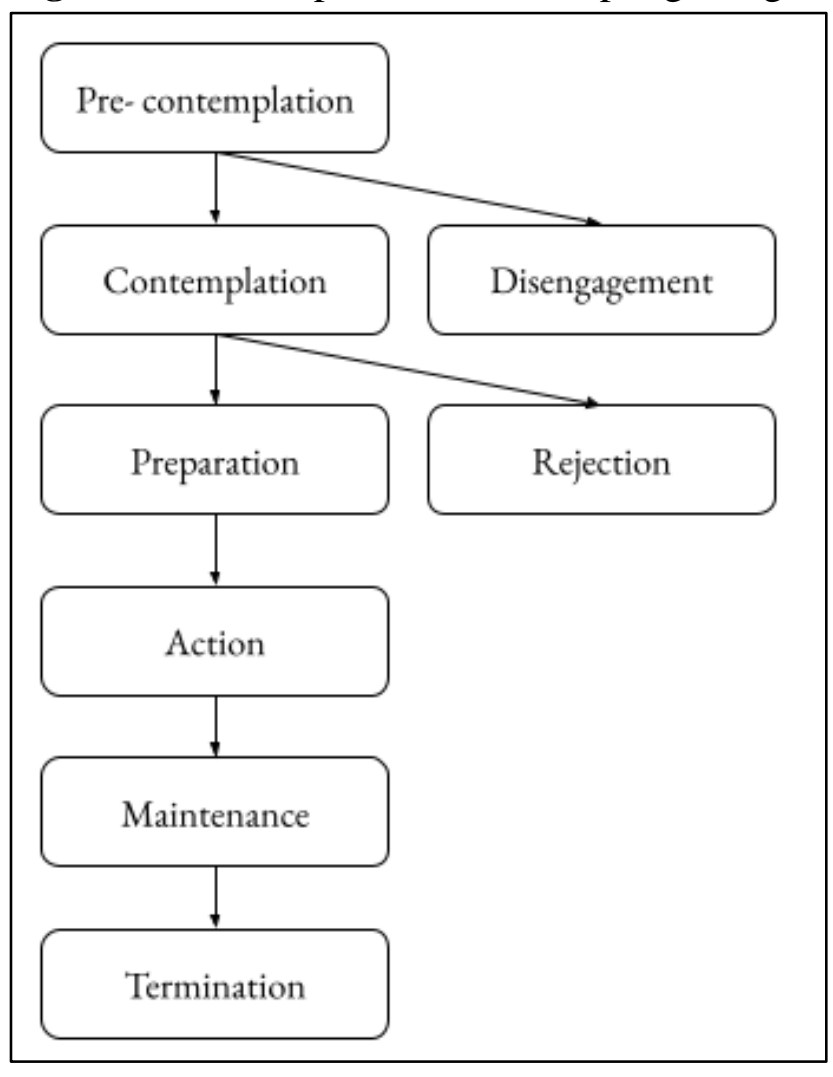

Crucially, these two decision points occur at or before the contemplation stage of the TTM when somebody begins to think about the issue of veganism, and as somebody is deciding whether to adopt the behaviour change. Indeed, there is a rich literature exploring the social and psychological mechanisms which influence meat consumption decisions. Furthermore, publications from academia and advocacy groups offer insights on factors which affect later stages of the model with respect to veganism, and factors relating to the processes of change.

Therefore, the purpose of this paper is to build on existing work which applies the stages of change model to veganism. In particular, we explore the social and psychological barriers to individuals moving through the stages of change towards veganism, how advocates can overcome them, and what further research is needed. The paper represents a guide for animal advocates to understand the social and psychological barriers would-be vegans may experience when they consider the issue, and what they can do to help them overcome those barriers.

\subsection{Social and psychological barriers}

There are an array of social and psychological biases which push against the efforts of animal advocates at each stage of moving an individual through the stages of change towards veganism. As well as these individual biases, the sociocultural context for consumers in the West is one where animal consumption is the norm, and those who refrain from it are 'othered'. 
A deeper understanding of the social, cultural, and individual psychological factors which support the meat paradox, and the relationships between them, may help animal advocates to more effectively move people along the stages of change, identifying appropriate interventions and tips to move people to contemplation of the issue, preparation to change, taking action and maintaining the change. The phenomena discussed herein are listed in Table 2 next to the relevant stage of change.

Table 2: Stages of change towards veganism and relevant social and psychological biases.

\begin{tabular}{|l|l|}
\hline Stage of Transtheoretical Model & Relevant social and psychological biases \\
\hline Pre-contemplation & $\begin{array}{l}\text { Ignorance } \\
\text { Avoidance } \\
\text { Confirmation bias }\end{array}$ \\
\hline Contemplation & $\begin{array}{l}\text { Cognitive dissonance } \\
\text { Motivated reasoning } \\
\quad \text { Self serving bias } \\
\end{array}$ \\
& $\begin{array}{l}\text { Status quo bias } \\
\text { Scale insensitivity }\end{array}$ \\
& Carnism \& speciesism \\
& Social representations \\
& Social norms \\
\hline Preparation & Habit \\
& Willpower \\
\hline Action & Social Identity \\
\hline Maintenance & Helping relationships \\
\hline Termination & \\
\hline & \\
\hline
\end{tabular}

In this paper, we discuss each of the social and psychological factors which represent barriers at each stage of change towards veganism in the Transtheoretical Model of Change (TTM). We argue that animal advocates should conceive of each individual as being at a different stage of this process, and therefore requiring different communications to move them to the next stage and, importantly, having different psychological obstacles to overcome.

Although there are good arguments for reducing animal product consumption for environmental or health reasons, here we focus on the moral considerations of using animals for food. Morality is a powerful motivator for behaviour change, and moral reasons for veganism are popular among those who convert (Cooney, 2014a). While health concerns have been widely studied using the TTM, the model has yet to be applied widely in moral contexts. Thus, the stages here illustrate a form of philosophical awakening whereby somebody decides to become vegan primarily for moral reasons (e.g. concerns surrounding animal harm and cruelty, duties of environmental care or the sanctity of life; Singer, 1975). When considering meat reduction for other reasons, it is possible that other barriers and considerations would become more relevant, though many may be similar. 


\section{Pre-contemplation}

The first stage of the TTM is pre-contemplation: where meat consumers are not considering changing their behaviour. Evidence suggests that around $40 \%$ of those engaged in problematic behaviours are at this stage (Prochaska \& Velicer, 1997) and this seems to be somewhat consistent with recent data on meat consumption (Arnaudova, Brunner \& Götze, 2021; Hielkema \& Lund, 2021; Klockner \& Ofstad, 2017; Wolstenholme, Carfora, Catellani, Poortinga \& Whitmarsh, 2021) ${ }^{1}$. Meat consumers at this stage may simply be unaware of the negative impacts of their behaviour, or they may be actively avoiding thinking about it. Indeed, there is evidence for both ignorance and avoidance in the case of animal farming and meat consumption.

\subsection{Ignorance}

Survey findings suggest that the public are mostly ignorant about the issue of animal farming (Cornish, Raubenheimer \& McGreevy, 2016). In one report of UK workshops on animal welfare, most participants admitted to knowing very little about how chickens were farmed for meat (Hall \& Sandilands, 2007). Similarly, the majority of respondents to a US survey could not name a single source to obtain information about animal welfare (McKendree, Croney \& Widmar, 2014). Recent research has found that the public are largely uninformed and often inconsistent with respect to their views on this topic (Alonso, González-Montaña \& Lomillos, 2020).

Not only are people unaware of facts around animal farming, but their assumptions tend to be incorrect. Reese (2017) found that $58 \%$ of U.S. consumers think 'most farm animals are treated well'. In reality, over 99\% of US farm animals live on factory farms (Reese, 2017). Evidently, most meat consumers hold objectively incorrect beliefs about the welfare of farmed animals.

Knowledge about animal welfare has been linked with concern for animal welfare. Interestingly, this link appears to be bidirectional (Cornish, Raubenheimer \& McGreevy, 2016; Eurobarometer, 2006; Heleski \& Zanella, 2006). In other words, concern about animal welfare causes people to seek information about animal welfare, and exposure to information about animal welfare increases concern about animal welfare. In fact, knowledge about animal welfare is a stronger predictor of concern for animal welfare than demographic factors (Eurobarometer, 2006).

As well as a lack of awareness of animal welfare issues in meat production, consumers may also be unaware that an alternative way of eating is possible. Studies have identified a lack of knowledge about where to find or how to prepare vegetarian food as a key barrier to meat-

\footnotetext{
${ }^{1}$ The proportion of meat-eaters in the pre-contemplation and contemplation stages is uncertain, since previous studies utilize the MAP framework where these stages are not differentiated, instead reporting that around $80 \%$ were in the pre-decision stage overall (Klockner \& Ofstad, 2017).
} 
free diets (Corrin \& Papadopoulos, 2017; Pohjolainen, Vinnari \& Jokinen, 2015; Schenk, Rossel \& Scholz, 2018). People may become aware of alternative ways of eating if they meet a vegan, or encounter vegan products or restaurants. One can therefore think of two kinds of awareness here: awareness of unethical practices in meat production (pushing away from meat) and awareness of appealing alternatives (pulling towards veganism).

For some small portion of the population, simple ignorance of common farming practices truly is the only barrier to veganism. This is evident from the numerous people who go 'vegan overnight' after learning about farm animal suffering (Lindstorm, 2017), although a more gradual progression along the stages of change is more common (Grassian, 2019). In either case, providing people with information about animal farming (or 'consciousness raising' in the parlance of the TTM) is likely to be an effective way to encourage them to move to the next stage of contemplation.

Most people are ignorant about animal welfare in agriculture, and some are ignorant about the existence of alternatives. This ignorance is a problem, since it precludes the possibility of caring or taking action. As well as those who are literally ignorant of the facts, it is likely that many more are willfully ignorant or feigning ignorance to avoid taking responsibility (Harper $\&$ Henson, 2001). These people may engage in avoidance.

\subsection{Avoidance}

Avoidance is what Salehi, Diaz and Redondo (2020) refer to as 'disengagement' where people do not even make it to the contemplation stage. Avoidance is the attempt to disengage with a stressor in order to mitigate the negative emotional consequences of dealing with it directly (Gautam \& Passi, 2014; Roth \& Cohen, 1986). Evidence suggests that meat-eaters tend to avoid thinking about farm animal suffering, and some have argued that society is partly structured to make such avoidance easier (Bastian \& Loughnan, 2017).

Research shows that meat-eaters tend to actively avoid thinking about the animal origins of meat. One survey found that $67 \%$ of consumers said they did not think about farm animal suffering when purchasing meat (Signicom, 1997). Moreover, Kunst and Hohle (2016) found that meat which resembles an animal evokes more empathy in meat-eaters than processed and packaged meat. Many meat-eaters might love sausages, but find seeing a whole skewered pig upsetting. The study also demonstrated that replacing 'beef/pork' with 'cow/pig' on menus lead to increased willingness to order a vegetarian option instead. Just the name of the animal was enough to put people off eating it.

Joy (2011) makes the case that society facilitates the avoidance of thinking about farm animal suffering in a number of ways. Certainly, serious discussions of farm animal suffering are generally absent from mainstream media (see Section 2.3). As Rothgerber (2014a) has argued, the physical isolation of factory farms and slaughterhouses means that such places are out of sight and out of mind. Similarly, packaged meat usually does not resemble an animal, 
and the English language uses euphemisms like 'beef' and 'pork' to refer to the body parts of some animals (Kunst \& Hohle, 2016).

Many studies examining the effectiveness of different pro-vegetarian materials have found evidence of avoidance amongst meat-eaters (Bryant, 2019a). Cooney (2014b) compared vegetarian literature with photos of animal suffering, happy animals, people, or food. The study found that images of animal suffering were the most effective in encouraging people to want to eat less meat when they saw it, but also attracted the least attention: people tended to avoid images of animal suffering.

Similarly, Faunalytics (2012) studied the effectiveness of four different pro-vegetarian videos focused on either animal cruelty, animal individualisation, environmental arguments, or health arguments. Again, they found evidence that a focus on animal cruelty was the most effective in terms of reducing intended animal product consumption, but they also observed that viewers of this video most often stopped watching before the end of the video.

That somebody would seek to avoid thinking about this issue is some evidence of their discomfort with contemplating animal cruelty. Again, the cure appears to be patient consciousness-raising, inviting those who are in the pre-contemplation stage to collide with the reality of animal farming as frequently and as graphically as possible. The avoidance of such realities is facilitated by another psychological tendency: confirmation bias.

\subsection{Confirmation bias}

Confirmation bias refers to the tendency to selectively pay attention to information which affirms, rather than refutes, one's existing worldview (Klayman, 1995; Nickerson, 1998). There exists plenty of evidence of confirmation bias with respect to information about farm animal welfare. Meat-eaters tend to avoid images of animal cruelty (Cooney, 2014b), and often assume that evidence of animal abuse is agenda-driven and not trustworthy (Lentz et al., 2018). Meanwhile, the information consumers pay most attention to on labels of animal products are expiry date, species name, weight, and price - information about the production method (e.g. free-range) receives far less attention (Verbeke \& Ward, 2006; Verbeke et al., 2008; Verbeke, 2009).

Consumer-demand-driven media appears to conspire in this, too. Given that the vast majority of the population eat animals, it is unsurprising that media coverage of veganism and related issues has tended to reflect this preference. Cole and Morgan (2011) found that UK newspapers tended to frame veganism as defying commonsense, discredit veganism as difficult or impossible in practice, and portray vegans as capricious extremists. Although these messages may be appealing to a meat-eater who is seeking justification for their behaviour, none of them actually represent an argument against the ideas underpinning veganism. Rather, the media rely on readers accepting these presentations uncritically, and it seems that most meat-eaters are happy to do this because it serves their interests (Buddle, Bray \& Ankeny, 2018). 
Cole and Morgan (2011) show how the media covers veganism in a way which caters to audiences' confirmation bias. However, perhaps more important than what the media says about veganism is what it does not say. According to agenda-setting theory (McCombs \& Shaw, 1972), the media does not tell the public what to think per se, but rather what to think about. Topics which receive more prominent media coverage are generally considered more important by the public (Dearing \& Rogers, 1988). The lack of media coverage of veganism and animal rights therefore enables most people to continue ignoring these topics.

Since media coverage of an issue is typically prompted by specific events related to the issue (Botelho \& Kurz, 2008; Marks, Kalaitzandonakes, Allison \& Zakharova, 2003), one can expect that more coverage could result from new research publications, undercover investigations of farms, and co-ordinated commercial events such as Veganuary. Creating events for the media to report on and attaching the message of veganism may be a feasible way to raise consciousness around veganism and related issues.

\section{Contemplation}

With successful consciousness raising, meat consumers can move to the next stage of the TTM: contemplation. Similarly to the pre-contemplation stage, evidence suggests that around $40 \%$ of those engaged in problematic behaviours are at this stage (Prochaska \& Velicers, 1997). Again this may be similar for meat-eaters (Klockner \& Ofstad, 2017) ${ }^{1}$. During this stage, individuals will reflect on the behaviour, its impact on others and whether they want to continue it (Prochaska \& Velicers, 1997).

According to the TTM, individuals can often get stuck at the contemplation stage and procrastinate about changing their behaviour for months or years without making a decision (Prochaska \& Velicers, 1997). This is the stage where social psychology is likely to be the most useful. In this section, we will elucidate the many cognitive and social processes individuals are engaged with as they contemplate veganism.

\subsection{Cognitive dissonance}

One of the central processes driving contemplation about the morality of eating animals is cognitive dissonance, the discomfort one experiences upon discovering conflicting beliefs and behaviours. This unpleasant feeling likely explains why people tend to avoid thinking about farm animal suffering - indeed, evidence suggests that most people, when asked, will agree that the way we treat animals in the food system is regrettable. For example, Reese (2017) found that $70 \%$ of US consumers had 'some discomfort with the way animals are used in the food industry'. This survey also found paradoxically high support for animal rights policies. Notably, $49 \%$ of U.S. consumers support a ban on factory farming. Incredibly, $47 \%$ support a ban on slaughterhouses, whilst fully one third support a complete ban on animal farming. This is in a population where the vegetarian population is under $10 \%$ (Gallup, 2018). Clearly, there is a disparity here between consumer beliefs and their behaviour: if they 
are eating meat (i.e. not vegetarian), they are supporting the animal farming and slaughterhouses they claim to oppose.

While this research has focused on the West, Anderson and Tyler (2018) found that Brazil, Russia, India, and China (often referred to collectively as the 'BRIC' countries which are rapidly industrializing) had comparable levels of concern for animal welfare to the US, and in some cases higher concern. Therefore it seems that similar proportions of the population around the world think there are harmful and morally relevant consequences of eating meat. However, with the exception of India, vegetarianism in these countries is also extremely low (Anderson \& Tyler, 2018).

Therefore, billions around the world are actively taking part in a system of needless imprisonment, maiming and slaughter, which, by their own standards, is unethical (see Reese, 2018). It is likely no exaggeration to say that this is one of the deepest and most widespread moral dissonances of our time.

\subsection{Motivated reasoning}

Motivated reasoning can also be a barrier for individuals at the contemplation stage of the TTM. According to Kunda (1990, p. 480), 'There is considerable evidence that people are... likely to arrive at conclusions that they want to arrive at, but their ability to do so is constrained by their ability to construct seemingly reasonable justifications for these conclusions.' Somebody who eats meat, and who does not want to stop eating meat, has a lot to lose when it comes to thinking about the ethics of animal farming. Eating meat is cheap and convenient, and it would be difficult to avoid (Bryant, 2019b). Eating meat is also just nice: for most people, stopping eating meat would be a major personal sacrifice in terms of enjoyment and convenience (Piazza et al., 2015).

This leads to extremely motivated reasoning on the topic of farm animal suffering. The result is that many omnivores, most of whom scarcely think about animal ethics (Signicom, 1997), often appear confident in dismissing clear evidence of animal abuse as purely agenda-driven (Buddle, Bray \& Ankeny, 2018). The literature on this topic has tended to focus on individuals' motivations to see themselves as good people and view their own behaviour as ethical. Indeed, there is considerable evidence to support the view that self-serving biases play a central role in thinking on this topic. However, we argue here that reasoning around meat consumption is also motivated by a desire to see society as ethical and just.

\subsubsection{Self serving bias}

People are generally motivated to see themselves in positive ways, and to present themselves positively to others (Shepperd, Malone $\&$ Sweeny, 2008). This results in a number of selfserving biases, which distort one's thinking to increase self-esteem (Myers, 2015). Seeing oneself as a good person is a major motivation which affects reasoning on moral topics in which one's behaviour is implicated. As Campbell and Sedikides (1999) have shown, threats 
to an individual's self-image increase self-serving biases. The literature indicates that this desire for a positive self-image consonant with one's behaviour is a major source of motivated reasoning on the topic of farm animal suffering (Bastian \& Loughnan, 2017).

It is difficult to overstate what is at stake in the omnivore's dilemma. When thinking about this topic, the omnivore can (a) attempt to justify the suffering inflicted on farm animals, (b) give up animal products, or (c) simply live with the dissonance of knowing that they are supporting needless animal cruelty. It seems that, for most people, (b) and (c) are unacceptable. Accordingly, Loughnan, Bastian and Haslam (2014, p. 104) argue that omnivores experiencing 'the meat paradox' alter their beliefs about themselves ('the eater'), about animals ('the eaten'), and about meat consumption ('the eating').

First, with respect to beliefs about themselves, omnivores tend to underestimate the frequency with which they consume meat, particularly when they are in dissonance-inducing situations (Rothgerber, 2014a). This is an issue for research on animal product consumption because the moralised nature of the issue likely increases social desirability bias in self-reported behaviour and attitudes (Peacock, 2018). The tendency to hold unlikely beliefs about oneself with respect to meat consumption is demonstrated neatly by Reese (2017). His survey found that while $58 \%$ of U.S. consumers think that 'most farm animals are treated well', $75 \%$ think that the animal products they personally usually buy are 'from animals that are treated humanely'. This difference represents a self-serving bias, since people assume their own behaviour is more moral than that of others. (As discussed, the majority of people are wrong on both counts, since it is estimated that fewer than $1 \%$ of the animals killed for foods are produced outside factory farms in the USA (Reese, 2017)).

Second, with respect to beliefs about animals, Loughnan, Bastian and Haslam (2010) demonstrate how eating meat can change these. In an experimental study, people answered questions about cows' ability to feel pain and the morality of killing them - after first being given a snack of either nuts or beef jerky. Those given beef jerky assigned significantly less moral status to cows and showed significantly lower concern for animals in general. Lower regard for animals appears to have been exacerbated, in this case, by recent meat consumption. It is reasonable to extrapolate, therefore, that more frequent meat-eaters are likely to be subject to this bias more often and to a larger extent. Piazza and Loughnan (2016) also found that information about the intelligence of tapirs, but not pigs, led to higher moral concern for the relevant animal; it appears that an increase in moral concern for pigs was prevented by a form of motivated reasoning, since participants were themselves eating pigs.

Third, with respect to beliefs about meat consumption, Rothgerber (2014a) shows that meateaters experiencing dissonance reduce their perceived choice in the matter. The author demonstrated that many omnivores who confronted this dilemma claimed that they had little choice in whether to eat meat. Similarly, Piazza et al. (2015) identify Necessity as one of 'the four Ns' which are frequently used to justify meat consumption (alongside Normality, Naturalness, and Niceness). Attributing one's shortcomings to circumstances beyond one's 
own control is a common self-serving bias, referred to in the literature as establishing an external locus of control (Twenge, Zhang \& Im, 2004).

There is evidence, therefore, of omnivores exhibiting self-serving biases when reasoning about animal product consumption.

\subsubsection{System justification bias}

System justification theory posits that people are motivated to justify the existing social order (Jost, Banaji \& Nosek, 2004). In contrast to self-serving biases in which individuals are seen as motivated to believe positive things about themselves, system justification theory sees individuals as motivated to believe positive things about their society, principally that the society is just. This is similar to Furnham's (1993) concept of 'just world beliefs' - a bias in which people assume justice will be done, sometimes by mysterious or spiritual means. Some psychological literature talks about 'existence bias' - Eidelman and Crandall (2012, p.270) state that 'people treat existence as a prima facie for goodness'. In other words, most people tend to assume that there must be a good reason for things to be the way they are. Of course, unless one resists this heuristic, one will conclude that one ought to oppose change of any sort, and will be incapable of detecting moral blind spots of any kind.

In this case, reading about the suffering of farm animals, and considering that this is happening to millions of animals right now can be overwhelming. If one properly feels the weight of this, it quickly becomes galling that society is complicit in this. Most people generally want to believe that there is order and justice to the world, and that such outcomes, if they truly were so terrible, would simply not be allowed to happen. Most people want to believe that there must be a good justification for doing this, even if they do not have it immediately to hand. For many people, the very fact that meat-eating is so widespread serves as evidence that it is morally acceptable. As Leenaert (2017) puts it, 'Most people eat meat because most people eat meat.' Normality is another of Piazza et al.'s (2015) four Ns which represent common justifications given for meat-eating. However, the fact that most people eat meat is, of course, not evidence that it is morally justifiable.

Some people are more likely to appeal to this kind of justification: Dhont, Hodson and Leite (2016) demonstrate that social dominance orientation (SDO) is a key factor which accounts for the oft-observed correlation between prejudice against human outgroups (i.e. racism) and prejudice against animals (i.e. speciesism) (Caviola, Everett \& Faber, 2019; Dhont, Hodson et al., 2014). Social dominance orientation, the tendency to support group-based dominance including racism, sexism, and homophobia, accounts for the relationship between speciesism and other forms of prejudice strongly (Dhont, Hodson \& Leite, 2016). Researchers, therefore, have dubbed this understanding of the relevant prejudicial structure as SD-HARM (Social Dominance Human-Animal Relations Model).

With respect to one's beliefs about their society, it is comforting to believe that society must have a real justification for condoning the maltreatment of animals. The alternative - the idea 
that there really is no good justification for causing intense suffering on an industrial scale - is simply too dire for most to consider. How could one feel comfortable in a society which allows such needless suffering?

Indeed, those who recognise this suffering often are not comfortable. In Herzog's (1993, p.115) interviews with animal rights activists, he writes that the activists '...talked about their frustration that public attitudes about the treatment of animals were not changing rapidly enough. They spoke of their sense of guilt when their behaviour did not match their ideals. Many were laboring under a heavy moral burden that other people do not bear.' This unpleasant sense of weltschmerz ${ }^{2}$ is one proposed mechanism for the link between vegetarianism and depression (Herzog, 2018). It is far more comfortable for a meatconsuming individual to believe that this suffering is not a problem, and that society and the world is just. This belief can stall behaviour change, and encourages meat-eaters to keep consuming meat instead of moving forward and changing their behaviour.

It may be frustrating to contend with motivated reasoning, but it is likely to be helpful to reflect on its origin in protecting one's image of oneself and one's society. Considering the topic in hypothetical non-personal terms, allowing the individual to save face in admitting inconsistencies, and informing them about the existence of such biases could help to overcome this situation, though more research is needed on the efficacy of these tactics.

\subsection{Status quo bias}

A related bias at play in the contemplation stage of TTM is the status quo bias. For anyone who is not born a vegetarian, eating meat represents the status quo from which veganism is a departure. In general, people have a preference for the status quo, even when alternative choices could be superior (Kahneman, Knetsch, \& Thaler, 1991; Samuelson \& Zeckhauser, 1988). The effect of this bias is pleasingly illustrated by Thaler (2009), who observes the difference in post-mortem organ donation rates between two neighbouring countries. In Germany, just $12 \%$ of people donate their organs after they die, while in the neighbouring Austria, a country uncannily similar in culture, the figure is $99 \%$. The difference is what happens as the default: Germans must opt in to donate their organs after death, whereas Austrians must opt out. Even with an issue which may be hugely consequential (such transplants are often a matter of life or death), and which one might think is particularly emotive, most people just stick with the default choice either way.

There is further naturalistic evidence of the status quo bias in the car insurance market in the US (Johnson, Hershey, Meszaros \& Kunreuther, 1993). In neighbouring Pennsylvania and New Jersey, two types of policy were offered: Pennsylvanians were offered as a default a more expensive policy with fewer restrictions on their rights to sue, whilst New Jersey

\footnotetext{
2 This German word translates literally as 'world pain', and refers to the sense of world-weariness one feels when considering how far the world is from perfect.
} 
residents were offered by default a cheaper policy with more restrictions on their rights to sue. In both states, the majority opted for the default choice.

Just as most Pennsylvanians have not necessarily decided to choose a more expensive car insurance policy and most Germans have not developed a strongly held opposition to organ donation, most meat-eaters have not performed a careful moral analysis before deciding to eat meat - it is just how things are (see Section 3.6). As we have demonstrated above, most meateaters prefer to avoid thinking about farm animal suffering, and the result is that many stick with the status quo of consuming meat.

A thought experiment illustrates how inertia maintains meat consumption for many people. One can imagine having been raised vegetarian in a predominantly vegetarian society (for example, some parts of India (Buncombe, 2019)). Having never eaten meat, and lived in a culture where this is normal, it seems unlikely that one would be inclined to kill an animal for food. The fact that one might imagine a reluctance to start eating meat when one has not previously done so might indicate that one's current preference for meat consumption is due in some part to simply the way things have always been. In fact, the argument that humans have always eaten meat is often explicitly deployed in defence of meat consumption (Piazza et al., 2015; Lowe 2016) - of course, always having done something in the past is no indication of its morality.

Status quo bias may be overcome by taking advantage of times of change in audiences' lives - for example, students moving to university may represent an audience who are particularly open to change, as they are already undergoing a large change of another kind (see Verplanken, Roy \& Whitmarsh, 2018). Campaigns such as 'Veganuary' capitalise on the New Year as a time for change to overcome the inertia around dietary change.

\subsection{Scale insensitivity}

A further factor which is relevant at the contemplation stage is scale insensitivity. It is bound to be difficult to properly appreciate the scale of the suffering caused by industrial animal agriculture. This is due to an interesting misalignment in the way people tend to think about morality and scale. Hsee and Rottensteich (2004) demonstrated that, when people rely on feelings, rather than calculation, they are largely insensitive to the scale of the stimulus, apart from reacting to its mere presence or absence. One implication of this is that particularly emotive stimuli are likely to elicit a response that fails to adequately account for the scale of the pain or pleasure demonstrated. Many people tend to fail to appreciate the difference in scale when they react emotionally.

In an experimental study Boyle, Desvousges, Johnson, Dunford and Hudson (1994) demonstrated that groups who were given the opportunity to save 2,000, 20,000 or 200,000 birds affected by an oil spill did not differ significantly in their willingness to donate, despite orders of magnitude in difference in outcome. Similarly, Kogut and Ritov (2005) have demonstrated that a single identifiable victim elicits more distress than a group of victims, 
and the presence of additional victims makes people no more likely to contribute to alleviating suffering. It seems that people are largely insensitive to the scale of emotional stimuli.

It is difficult to appropriately scale emotional responses to very large-scale suffering (Slovic, 2007). This renders most people unable to truly appreciate the scale of suffering involved in animal agriculture. If one learns, for example, that the UK slaughtered one million pigs last year, one is likely to experience this as a remote statistic rather than imagining the fear the animals experience in the moments before they have a knife pushed into their throats. Moreover, if one learns that the real figure is not one million, but ten million (Animal Clock, 2020), one's emotional reaction is unlikely to be very different.

This implies that the common advocacy message of focusing on the very high numbers of animals killed for food is likely to be ineffective. Indeed, recipients of such a message might be less likely to change if they perceive that many people support animal farming, or that their own behavioural change would be a drop in the ocean (Cialdini et al., 2006; Goldstein, Cialdini \& Griskevicius, 2008). Advocates should therefore focus on the quality of farm animals' lives rather than the quantity of animals.

\subsection{Carnism and speciesism}

At the contemplation stage, we must also consider some social and cultural factors. Individual decisions are unavoidably taken in a socio-cultural context. In this way, individuals may be blind to the social processes affecting their thinking and decision making. In the case of animal product consumption, there is an overwhelming culture of meat-eating in most Western countries, supported by a pervasive ideology known as carnism (Joy, 2011). The carnist worldview considers a small group of animals appropriate for human consumption or use. The idea of factory farming most species of animals seems bizarre and cruel, yet society finds it acceptable to factory farm cows, pigs, sheep, and some species of birds and fish. Carnism is pervasive and powerful at every level of society. The exploitation and killing of these animals is a deeply embedded part of human cultures, rituals, and traditions.

Carnism is rooted in speciesism - discrimination on the basis of species (Singer, 1975). Recently, psychologists have studied speciesism in greater detail, developing reliable scales for its measurement and demonstrating that it correlates with racism, sexism, and other discriminatory attitudes (Caviola, Everett \& Faber, 2019). Likewise, Dhont and Hodson (2014) found higher acceptance of animal exploitation and greater belief in human supremacy amongst those with right-wing ideologies and higher social dominance orientation.

Upon first encountering the concept of speciesism, one may be tempted to reject the idea that it is analogous to other forms of discrimination. It is intuitive to think that there are good reasons to discriminate on the basis of species - for example, it is common to argue that nonhuman animals have inferior cognitive abilities, have lower levels of sentience, or lack moral 
agency. However, as Caviola, Everett and Faber (2019) argue, none of these appear to be good reasons to reduce one's moral concern for beings within the same species. Most people would not condone affording fewer rights to a mentally impaired human who lacks cognitive abilities or moral agency - they may even increase their moral concern for such a person. Therefore, membership of a different species, rather than mental deficiencies per se, appears to be the basis for radically different treatment of some animals.

Views of this kind are often mistaken for a belief that humans and animals are morally equivalent. Of course, one does not need to believe this in order to believe that animals have sufficient moral value to avoid killing. Nonetheless, comparisons of animal and human suffering are often difficult to stomach. Mika (2006) found evidence that activist messages comparing animal agriculture to slavery and rape were likely to put people off engaging with the message. While it is possible that humans have a richer conscious experience than farm animals comprising 'higher order thoughts' (Carruthers, 1992; 2000), there is evidence that animals, like humans, can (and, in most farming systems, do) experience physical and emotional pain and distress. Nonetheless, in order to escape in-group bias, it is useful not to consider comparisons between animals and humans, but instead to consider comparisons between different species of animals.

As Caviola, Everett and Faber (2019) discuss, there is evidence of arbitrary and radical variations in society's treatment of different species of animals across cultures and time. It is well-known that cows are considered holy by many people in India (Attanasio \& Augsburg, 2018), and beef consumption in some parts is rare (Devi, Balanchar, Lee \& Kim, 2014). This example is not unique: other animals which are factory farmed were considered holy or sacred in different times throughout history. The Irish Druids considered pigs to be sacred, to the extent that their priests were known as 'swine' (Bonwick, 1894). In the Ancient Roman senate, 'sacred chickens' were used as omens to forecast the society's future (de Jacourt, 1765). Today in the West, all of these animals which have been considered sacred in other contexts, are farmed for food.

Conversely, horses, which now enjoy generally high status and are sometimes seen as pets in the West, were in the past regularly used for food (Gade, 1976). In the West, dogs are people's friends, companions, and pets. However, dogs are killed for food in Asia in their millions (Czajkowski, 2014), most famously at the Yulin dog meat festival, where they are publicly tortured with bludgeons and blowtorches to make their meat taste better (Giordano, 2019).

Perhaps the clearest example of speciesism for many is a comparison between dogs and pigs. Intuitively, these species seem very similar. Indeed, empirical evidence strongly suggests that pigs and dogs have very similar cognitive and emotional capacities - in fact, pigs are generally considered to be more intelligent (Broom, Sena \& Moynihan, 2009; Mendl, Held \& Byrne, 2010; Low et al., 2012). It is difficult, when one looks, to find the difference which makes it acceptable to put a pig, but not a dog, into a gas chamber for food. 


\subsection{Social norms}

One of the major implications of a carnistic culture is that meat-eating is normal: those who choose not to eat meat are deviating from a social norm on which there appears to be overwhelming consensus. There are at least two ways in which the normality of meat consumption could be a barrier to adopting veganism.

First, an individual might infer from the overwhelming normality of meat consumption that, since so many people engage in this practice, there must be a good justification for it (Piazza et al., 2015). Moreover, since it is so normal, there is little or no social cost to eating meat, so there is no external motivation to pay attention to the issue. This may serve as a form of avoidance (a barrier to developing interest in the issue) or a form of motivated reasoning (a barrier to developing the desire to go vegan).

Second, an individual might actually have accepted the arguments for veganism, but decide that going vegan will violate the social norm, and therefore carry a social cost. Deciding to avoid meat out of personal preference, taste, or concern for one's own health is a very different proposition from a moral objection (Rothgerber, 2014a) - the latter carries the implication that other people ought not to eat meat, too. Bringing animal slaughter to the attention of a meateater is a fairly confrontational act - this is likely to feel especially uncomfortable for those inclined towards veganism, who may be conflict-averse as a result of tending to be more agreeable and introverted than average (Cooney, 2014c; Keller \& Siegrist, 2015; Kesller et al., 2016; Mõttus et al., 2013). Therefore, a desire not to 'rock the boat' may stop people from going vegan even if they accept the arguments.

These two levels of distortion by social norms are analogous to those observed by Asch (1951) in his classic conformity experiments. Of the subjects who yielded to group pressure and modified their responses, some reported afterwards that they thought the group majority must be correct, whilst others knew they were wrong but did not want to break social cohesion. The distortion occurs in one case at the level of belief, and in the other merely at the level of behaviour.

Schenk, Rossel and Scholz (2018) found that social norms exhibited a significant effect on intended meat consumption. There was a strong effect on meat avoidance intentions from the normative expectations of friends, family, and collegues, and a weaker effect from the number of vegetarians in somebody's network. This is evidence that both knowing more vegetarians, and perceiving that vegetarianism is an expected norm in your social environment is likely to influence one's decision.

Cooney (2014a) reported on survey responses including some meat-eaters who said they wanted to go vegetarian, and some who said they did not want to. He observed that the most common reason given by omnivores who did not want to go vegetarian was, by far, taste. Conversely, the most common reasons given by omnivores who did want to go vegetarian and had not done so was convenience, followed closely by family, and then cost. These data appear 
to support the idea that people tend to have different concerns at different stages of the transition towards veganism: those who are in the contemplation stage (i.e. they do not want to go vegetarian) were concerned with taste, whereas those who were in the preparation stage (i.e. they already had the desire to go vegetarian) were concerned with more pragmatic factors about how to execute the transition. This is also reflected in the findings of Bryant and Dillard (2020) who studied the intentions of students who watched a presentation arguing for plant-based eating. The results indicated that students who developed an intention to reduce their animal product consumption were more likely to report practical factors as their primary barrier to acting, whereas those who did not intend to act were more likely to report taste as their main concern.

Advocates can contribute to changing social norms by sharing their honest views of animal ethics, and change perceived social norms by highlighting salient examples of how other people are reducing their meat consumption.

\subsection{Social representations}

A further relevant concept at the contemplation stage is social representations. Moscovici (1961) argues that one of the key ways people make sense of our shared social world is with social representations, defined as our abstract shared renderings of concepts in the world. These representations serve to establish order so that individuals can orient themselves when interacting with the world (Moscovici, 1981), and most people within the same culture likely have similar social representations of the concepts of meat, farmers and farm animals, and veganism.

Funk, Sutterlin and Siegrist (2020) experimentally investigated the stereotypes subjects attributed to a host who served a vegetarian (vs. meat) menu. Their findings indicated that, compared to a host serving a meat menu, the vegetarian host was seen as significantly more concerned with animal welfare and personal health, as well as trend conscious and alternative. The traits attributed to the vegetarian host in this study demonstrate some of the associations people have with vegetarianism and to some extent portray the social representations of vegetarians. They are concerned with animal welfare and their health to an unusual extent, and are trendy and alternative - they are not, according to this representation, like normal people.

Our social representation of meat, on the other hand, is one of valorisation and fetishization. Meat is often seen as central to dishes (Melendrez-Ruiz, Chambaron, Buatois, Monnery-Patris \& Arvisenet, 2019) and is associated with wealth and power (Aveli, 2013; Rothgerber, 2013; Ruby \& Heine, 2011). Communal meat consumption plays a central role in many traditions, including Sunday roasts, Easter lamb and Christmas turkey, and may develop warm associations with family gatherings (Abarca \& Colby, 2016). Although many consumers are ambivalent about meat production on reflection (Van der Weele \& Driessen, 2019), common social representations of meat do not consider animal ethics, possibly because they are created socially and therefore aim partly to facilitate social cohesion. 
Finally, social representations of farmers and farm animals are crafted by the language used in relation to animal farming. As Croney and Reynnells (2008) argue, in English, euphemisms and metaphors like 'crops' 'units', and 'harvest' replace words like 'herds', 'animals' and 'slaughter' to make the process seem less violent. As the authors put it, 'Semantic obfuscations rampant in the language of modern farm animal production reflect underlying ambivalence about transparency relative to many standard industry practices.' (Croney \& Reynnells, 2008, p.387) In other words, if common representations of animal farming were an accurate representation of what the process entails, consumers 'might consequently refuse (as is their right) to purchase particular products, thus potentially causing significant short-term industry losses.' (Croney \& Reynnells, 2008, p.387). Clearly, there are financial incentives to controlling the social representation of farming.

Recent research has looked at ways that social representations can be influenced to create behavioural change. Jaspal and Nelrich (2020) have argued that, in order to create positive responses to the COVID-19 crises, social representations of the disease and its mitigation strategy must avoid the perception of extreme threats, be understandable to a range of communities, and provide clear behavioural prescriptions. In a similar way, advocates of meat reduction could use this framework to understand how the relevant concepts are generally understood, and how this could be influenced. Messages should be clear in their depiction of how individuals' actions are linked to easily understandable consequences.

\section{Preparation}

As Salehi, Diaz and Redondo (2020) have depicted, some people may move past the contemplation stage of the TTM, and reject the ideas of veganism wholly. Many of those who do likely have experienced some or all of the barriers to change described in the previous section. For those who do decide to change, they move on to the preparation stage of the TTM. At this stage, people have made a decision to change their behaviour in a positive direction, and are intending to change the behaviour within the next six months (Prochaska \& Velicer, 1997). During this stage, people take steps towards the intended behavioural change, which might include trying out meat replacement products, preparing some vegetarian meals, or learning more about veganism (Mendes, 2013).

It is estimated that around $20 \%$ of those engaged in a problematic behaviour are at the preparation stage. Again, empirical data on meat reduction appears to confirm this, with Lacroix and Gifford (2019) identifying $14 \%$ of their sample as people ready and willing to reduce their meat consumption. Similarly, Bryant (2019b) observed $16 \%$ of a UK sample saying that they intended to reduce their meat consumption within the next month. However, even at this stage of the TTM there are still two significant psychological barriers for meatreducers hoping to continue their journey towards veganism: changing habits, and selfliberation. 


\subsection{Habit}

Even with the best of intentions, it is easy to act otherwise out of habit, particularly with respect to a behaviour so long ingrained and so frequently performed as choosing food. Even someone who is utterly convinced of the arguments for veganism may not change their behaviour out of habit. As Wood and Rünger (2016) argue, habits represent the default responses in choice scenarios, and drive choices more frequently than deliberate goal pursuit. The authors elaborate that habitual behaviours often entail a short-term change in goal priorities - this is reflected in food choice data consistently showing taste and convenience to be stronger drivers of food choice than factors such as ethical concerns or health (Fotopoulos, Krystallis, Vassallo \& Pagiaslis, 2009; Januszewska, Pieniak \& Verbeke, 2011). Bastian and Loughnan (2017) have argued that meat consumption, like other morally dubious behaviours, becomes habitual, and many people tend to engage in such behaviours with 'little reflection and relatively high frequency' (p. 284).

Food choices are likely to be affected by habit, because they are often made in the same context, and are therefore subject to the same environmental cues (Wood, Labrecque, Lin \& Rünger, 2014). For example, choosing one's lunch might occur in the same cafeteria or shop display which prompts default selection of one's usual choice. Further features of habitual behaviours include choices made with limited thought and rigidity (Seger \& Spiering, 2011, Smith \& Graybiel, 2013), features which again are likely to apply to food choice. In the language of TTM, individuals can engage in stimulus control, i.e. deliberately design their environment and routines so that they avoid temptations. In the case of veganism, not keeping meat or animal products in the house is likely to be a good way that individuals can control their stimuli as they prepare to change their diet.

Strategies and tools have been developed tools to help motivated individuals overcome these habitual choices. Camp and Lawrence (2019) demonstrate the efficacy of a computerised 'Response Inhibition Training' task for reducing the propensity to carry out bad habits, including meat consumption (Lawrence et al., 2015; Adams et al., 2017). In the training, subjects respond to pictures of plant foods, but do not respond to pictures of meat; compared to a control group, those who took the training significantly decreased their meat consumption (Camp \& Lawrence, 2019). Other promising research has shown that selection of vegetarian options increases significantly when these dishes are presented as the default (Campbell-Arvai, Arvai \& Kalof, 2014; Hansen, Schilling \& Malthesen, 2019). This is an example of an intervention which food outlets could adopt, or regulators could require, to help consumers who already want to reduce their meat consumption to overcome the habitual selection of meat.

\subsection{Self liberation}

In the TTM, self-liberation refers to the belief that one can change the behaviour and the continued commitment to do so. According to Prochaska and Velicer (1997, p.40), selfliberation is 'what the public calls willpower'. Metcalfe and Mischel (1999, p.3) characterise 
the research on willpower as suggesting a 'hot/cool-system' whereby the impulsive and reflexive 'hot' system attempts to drive an individual based on emotionally salient stimuli (such as meat they find appealing) and the contemplative unemotional 'cool' system attempts to drive the individual on the basis of their reasoned intentions. The authors argue that the result in a given situation depends on a number of environmental and individual factors. It is likely that this dynamic is at play with respect to resisting meat - indeed, some experimental work uses tempting food as a willpower-depleting stimulus (Baumeister \& Vohs, 2003).

Individuals may vary in how much willpower they can summon to avoid meat. For example, individuals vary with respect to their attitudes towards harming farm animals (Caviola et al., 2019) - some people are higher in empathy than others (Hogan, 1969) and are presumably more disposed to care about animal suffering. These people may naturally have more willpower to avoid animal products.

Additionally, individuals may vary in how much willpower they require to avoid meat. Individuals have different levels of meat attachment (Graças, Calheiros \& Oliveira, 2015): in particular, those with a high hedonistic value derived from meat and high dependence on meat will require more willpower to continually avoid meat (Lentz, Connelly, Mirosa \& Jowett, 2018). For people with low meat attachment scores, giving up meat is less of a sacrifice, and therefore requires far less willpower. Moreover, since taste, price, and convenience are known to be major barriers to vegetarianism (Schenk, Rossel \& Scholz, 2018; Bryant, 2019), it can be inferred that many people with access to high quality affordable alternatives to animal products make less of a sacrifice when giving up meat, and therefore require less willpower to change their consumption.

Whilst habitual purchase of meat can be characterised as automatic, and is thus welladdressed through Lawrence et al.'s Responses Inhibition Training, lack of willpower describes a situation where the individual has interrupted the automatic process to consider their food choice, but nonetheless chooses meat. Gollwitzer and Sheeran (2006) found strong evidence for the effectiveness of implementation intentions in overcoming this situation. That is to say, one can increase adherence to an intended behaviour (e.g. being a vegan) by planning in detail when one anticipates challenges (e.g. immediately before mealtimes), where one is likely to be (e.g. at home, or at work), and how one will deal with these challenges to behave in line with their goal (e.g. having tasty pre-prepared vegan food ready and available). Planning implementation intentions is likely to significantly increase motivated individuals' ability to adhere to a vegan diet.

\section{Action}

This is the penultimate stage of TTM where the individual has taken action to change the target behaviour within the last 6 months (Prochaska \& Velicer, 1997). Researchers stress the importance of having a defined and stringent threshold of behaviour the person must cross before they are considered to have advanced from the preparation stage to the action stage. In 
most cases, this is complete abstinence from the problematic behaviour, e.g. giving up meat or animal products.

\subsection{Social identity}

One relevant concept at the action stage is social identity. When an identity is made salient, individuals are more likely to exhibit behaviours in line with that identity. Chattaraman, Lennon and Rudd (2010) found that bicultural subjects could be induced to prefer one brand or another (each associated with one of their cultural identities) by priming them to view one identity as more salient. Identities affect individuals' behaviours in a variety of contexts, including food.

As Fischler (1988, p. 275) writes, 'Food is central to our sense of identity. The way any given human group eats helps it assert... the otherness of whoever eats differently.' Identities are usually much more salient for groups which represent minorities or deviations from the norm. The construction of the category 'vegetarian' likely contributes to greater dietary adherence, both in vegetarians and in meat-eaters (Blake, Bell, Freedman, Colabianchi \& Liese, 2013; Carfora, Caso \& Conner, 2017). However, the need to identify as a vegan or vegetarian in itself may discourage some meat-reducers from action, particularly if identification becomes a pre-requisite for attempting the practice (Kurz, Prosser, Rabinovich \& O’Neill, 2019). If, at a family meal, a meat-reducer needs to 'out themselves' as 'vegan' to access the restaurant's vegan menu, this may put people who are not strongly identified off trying. In social situations, meat-reducers may wish to avoid the stigma and social-interactional trouble associated with "being a vegetarian or vegan", particularly when meat-eating is culturally significant or a normative practice (Minson \& Monin, 2012). Identity can thus be a large barrier for action at this TTM stage.

Krpan and Houtsma (2020) experimentally manipulated the labelling of meat-free options in a menu selection-based hypothetical choice task. They found that labelling meat-free options as 'vegetarian' led to significantly lower selection of these dishes compared to labelling them as 'environmentally friendly' or 'refreshing'. This could be an indication that the label 'vegetarian' is uniquely off-putting to people who do not identify as vegetarian. Such a label may be taken to imply 'for vegetarians only'.

As well as forming part of one's social identity, food which people associate with childhood memories and cultural traditions can form an important part of their personal identities (Fischler, 1988). People typically prefer foods they are more familiar with (Raudenbush \& Frank, 1999), so many people maintain consumption of childhood dishes well into adulthood (Demory-Luce et al., 2004). Researchers have observed that mothers typically reproduce the food practices of their mothers, embedding food practices in families (Knight, O'Connell \& Brannen, 2014).

One interesting trend with respect to dietary identity is the emergence of 'flexitarianism' and 'reducetarianism' (Sachs, 2019). These are identities which express that one actively seeks to 
reduce, though does not entirely eliminate, their consumption of meat and animal products. Flexitarians vary in the extent to which they consider their diet central to their identity, and in their beliefs about carnism (Rosenfeld, Rothgerber \& Tomiyama, 2019). For example, whilst many flexitarians are concerned about their health and the environment, they are less likely to be primarily concerned with animal suffering compared to vegetarians and vegans (Cooney, 2014a). Such concerns may be seen as the domain of vegetarians and vegans, and not relevant to other identities.

Beyond viewing identities as static phenomena, Breakwell (2014) characterises identity as a process. In this framework, people behave consistently with existing and past versions of themselves (assimilation), whilst maintaining the possibility of changing (accommodation) and ultimately identity is a negotiated process of consistency and change (balance). This framework highlights the potential importance of continuity when considering the impact of identity changes on self-efficacy and self-esteem (Vignoles, Regalia, Manxi, Golledge \& Scabini, 2006).

It is likely that people who first give up meat do not yet consider themselves to be vegetarians. Assimilating this new behaviour of meat avoidance into a new identity as a vegetarian is likely to be one major way in which longer-term behaviour change can be achieved.

\section{Maintenance}

This is the final stage of TTM when an individual is maintaining the new positive behaviour, but may still experience temptations to perform the old behaviour. People in this stage changed their behaviour more than 6 months ago, but less than 5 years ago, and have not yet reached the termination stage where they no longer experience temptations (Prochaska \& Velicer, 1997). Asher and Green (2016) report that 53\% of lapsed vegetarians and vegans maintained their diet for less than a year, while 34\% lasted less than three months. Therefore, it seems likely that, consistent with TTM, relapse becomes less likely the longer the behaviour is maintained. Supportive relationships can uphold the newly established veganism.

\subsection{Supportive relationships}

The TTM prescribes supportive relationships as a process of change which is relevant to the maintenance stage, and research in the domain of vegetarianism and veganism appears to support the idea that membership in vegetarian and vegan communities is important to maintaining the dietary shift. That said, the existence of a supportive network may be relevant at all stages, including encouraging the shift from pre-contemplation to contemplation.

Asher and Green (2016) report that the overwhelming majority (84\%) of former vegetarians and vegans were not involved with any vegetarian or vegan communities such as vegetarian 
potlucks or online groups, compared to $71 \%$ of current vegetarians and vegans. This study also highlighted that $63 \%$ of former vegetarians and vegans said they disliked that their diet made them stand out, compared to just $41 \%$ of current vegetarians and vegans. Both comparisons indicate that closer social alignment with vegetarian and vegan communities could help people to maintain these diets.

In particular, supportive vegan friends can provide encouragement and accountability. Evidence shows that people with more vegetarian/vegan friends, and who perceive stronger norms around meat avoidance in their close social groups, are more likely to stop eating meat (Schenk, Rossel, \& Scholz, 2018).

Therefore, to help new vegetarians and vegans maintain their diets, membership in a vegetarian or vegan community is recommended. Online communities provide a low-effort option for regular engagement with vegan material, whereas local vegan groups might offer the opportunity to form more personal relationships with people who can support the change.

\section{Discussion \& Conclusion}

In this paper, we have examined social and psychological barriers to veganism at each stage of the TTM. It is important for animal advocates to be aware of these stages and their associated barriers, and actively consider where their audience might be in this process somebody who has never spent time thinking about animal welfare is going to require a different approach from somebody who is already convinced of veganism, but is yet to take action. Moreover, people at each stage of this process and beyond are subject to psychological, social and cultural biases which limit their thinking about animal suffering.

\subsection{Arguing about animals}

This paper has considered the journey to veganism from an ethical perspective in terms of animal suffering and animal rights. There are, of course, good reasons to reduce meat consumption from the perspective of the environment or public health. However, there are good reasons why advocates should not shy away from focusing on animal suffering.

Many of the central psychological processes involved in thinking about farm animal suffering are based on cognitive dissonance between caring about animals and eating them. If the meateater accepts the ethical argument for veganism, they must accept not only that they personally pay for unnecessary animal suffering, but that their society and everyone they know is complicit in this systematic cruelty. Evidently, these psychological barriers are sufficient for many people to be completely unmoved by moral arguments about animal suffering when it comes to reducing their own animal product consumption.

However, experimental evidence suggests that messages focused on animal suffering are on average more likely to lead to behavioural change than messages focused on health or the 
environment (Faunalytics, 2012; Doebel, Gabriel \& Cooney, 2015). Indeed, Cooney (2014a) found that health was the most commonly given motivation by meat-reducers, whilst the majority of vegetarians and vegans said they were primarily motivated by moral motivations including animal rights.

Importantly, arguments about the environment and human health diverge somewhat from arguments about animal suffering in their conclusions. Whilst red meat and dairy tend to have worse effects on the environment and human health (Ritchie \& Roser, 2020), their production typically entails much less animal suffering compared to the production of chicken and fish, which tend to be kept in far greater numbers and in far worse conditions (Tomasik, 2018). Therefore, advocates who deploy these arguments should be wary of a rebound effect whereby consumers reduce their consumption of red meat and dairy only to replace it with white meat, increasing animal suffering overall (Bryant, 2019). Happily, some evidence suggests this does not tend to happen, and meat reducers rather tend to reduce all types of meat consumption rather than increasing some (Vegan Outreach, 2016), but the evidence on this point is far from conclusive. It is important to develop the legitimacy of arguing on the basis of animal suffering, especially given ongoing research to mitigate the environmental and health costs of meat consumption (Dugan et al., 2011; Hulshof et al., 2012). That said, arguing on the basis of health and the environment is still useful to the extent that it produces the outcome of interest, i.e. reducing meat consumption.

\subsection{Further research}

Conceptualising the journey to veganism in this way highlights some areas in which research has a good understanding of human psychology on this issue, as well as areas which warrant further investigation.

First, it is not clear how many people tend to be at each stage of the TTM with respect to veganism. Although survey data can give some indication, and seem to be consistent with the 40/40/20 rule of thumb (Prochaska \& Velicers, 1997), some findings seem to be somewhat contradictory - surveys find that most people are at once ignorant of and uncomfortable about the conditions of farmed animals (Reese, 2017). It is unclear, therefore, whether mass communications aimed at shifting diets should assume these people are ignorant (and therefore should seek primarily to raise consciousness) or already have some desire to give up meat (and therefore should seek primarily to facilitate behaviour change). In reality, it is likely that people may progress along this process as and when they think about animal farming, but most of the time are not thinking about it, and are defaulting to avoidance, or disengagement.

Second, interventions can be developed to overcome specific barriers to specific stages of this process. For example, just as response inhibition can help overcome habitual meat selection in people who already have the desire to go vegan, certain arguments may be reliably more persuasive than others in moving somebody from contemplation to preparation - i.e. persuading them to accept the arguments for veganism. There may also be framings and 
topics which are more or less conducive to agreement on the principles of veganism. Future research might measure agreement with veganism in principle as an outcome measure (as well as actual or intended behaviour change). This may be more of a reliable measure, given substantial shortcomings in behavioural intention reporting on this topic (Peacock, 2018).

Third, some evidence suggests that education and training can mitigate cognitive biases (Dunbar et al., 2014). Advocates could therefore investigate effective ways to bring their audience's attention to psychological phenomena such as motivated reasoning and status quo bias to encourage them to reflect more critically on their views on animal products. Clearer thinking on this topic could be the first step to alleviating suffering for millions of animals.

\subsection{Implications for Advocates}

Based on this TTM model of transition to veganism, animal advocates should recognise the different stages of change towards veganism, segment their audiences accordingly, and tailor their messages to the audience depending on their current stage. While images of animal cruelty may be effective in moving somebody from precontemplation to preparation, response inhibition training and implementation intentions are more effective tools for moving somebody from preparation to action. Moreover, advocates should be aware of the cognitive and cultural biases acting on individuals as they contemplate the issue of veganism and move from precontemplation to action.

At the pre-contemplation stage, advocates must contend with ignorance, avoidance, and confirmation bias. Raising awareness of farm animal suffering is likely to be a valuable activity because so many people occupy this stage (Reese, 2017). This could include exposing people to the reality of farm animal suffering through public activism or media which shows the animal suffering entailed in farming. For some people, such messages will be their first encounter with the idea that farm animals suffer to make food - for others, they might be an important reminder of something they had been doing their best to ignore. In any case, further contemplation and action is contingent on farm animal suffering being in the audience's awareness. Advocates should consider placing messages where they are difficult to avoid, for example billboards and TV adverts

(Bryant, 2019b). Such messages, which would be non-targeted according to TTM, may be appropriate for those in the pre-contemplation stage, for example raising consciousness by simply putting the relevant facts in front of the audience. Messages also could be appropriate for reinforcing people's behaviour at later stages of the TTM (e.g. preparation and maintenance), serving as a crucial reminder and motivator for continued behaviour change. However, advocates should balance these psychological benefits against the risk of potential reactance or backlash, which may encourage observers to "switch off" or derogate advocates for being "preachy". Here, research suggests that focusing message content on facts about animal agriculture, and not making aspersions about the moral characteristics of the observer themselves may be more effective for encouraging behaviour change in people who have not yet converted (Bolderdijk et al, 2018). 
At the contemplation stage, advocates must contend with cognitive dissonance, motivated reasoning (both self-serving and system justification), status quo bias, and scale insensitivity. Motivated reasoning can be difficult to overcome, and can make persuasion difficult. Understanding the dissonance and motivated reasoning at play here may help advocates to approach the conversation more constructively. For example, it may be helpful to frame the conversation hypothetically at first so that the audience's own behaviour is not forefronted in a way which makes them feel implicated. Moreover, it may be useful to ask what evidence would change someone's mind on this topic - this might encourage somebody to be reflective if their view is insensitive to evidence. It could be helpful to simply explain cognitive dissonance and motivated reasoning so that the person can understand why they are thinking about the issue as they are. It should be noted that the efficacy of any of these techniques has not been verified

Moreover, scale insensitivity means that advocates should avoid focusing on how many animals are killed for food, and instead focus on how badly the animals are treated. The quality is likely to be more salient than the quantity. Indeed, highlighting the scale of animal agriculture could demotivate individuals, who might feel like their own food choices are a drop in the ocean.

Status quo bias can be overcome by taking advantage of other periods of change in an individual's life - for example, changing jobs or moving house are situations which will entail disruption to existing routines and habits, and these contexts are prime for establishing other new habits.

On the social level, these biases are reinforced by existing social norms and representations, which are underpinned by carnism and speciesism. Beyond being extremely normal to consume meat and animal products, the radically different treatment and outright commodification of some species of animals is such a part of the cultural fabric that it becomes invisible. Meanwhile, narrowly constructed social identities silo vegetarians and vegans into dietary categories of 'the other' whilst the relevant social representations create reassuring stories of jolly farmers rearing happy animals to produce hearty food. These barriers can be overcome to some extent by encouraging people to think about different cultural contexts - for example, dog consumption in China demonstrates that society's radically different treatment of pigs and dogs is arbitrary. Moreover, Joy (2011) has popularised the concept of 'carnism' partly to clarify that carnism - not just vegetarianism - is an active choice. In general, one can expect that the more people eschew meat and animal products, the weaker the cultural consensus on the morality of animal consumption will become.

At the preparation stage, those who have decided to stop eating meat still face barriers of willpower and habit. These individuals can increase their chances of success by using response inhibition training to decrease their habitual meat selection and implementation intentions to plan to avoid meat, thus requiring less willpower. Advocates can point their audiences towards such tools, as well as other sources of continuing inspiration and guidance. 
At the action stage, individuals have given up meat, and may contend with issues of identity. This is a sensitive stage where people are most likely to revert to meat, but assimilating the behaviour of meat-avoidance with the identity of a vegetarian could help people to stick with the commitment longer term.

At the maintenance stage, and throughout, supportive relationships and networks are likely to be important. Membership in vegan communities is likely to increase an individuals' chance of remaining vegan, and advocates should therefore seek to make these communities welcoming and inclusive places rather than exclusive clubs.

In conclusion, the animal advocate faces a formidable task in moving individuals through the stages of change towards veganism. Together, the biases occurring at each stage allow the majority of otherwise ethical and compassionate people to support and be complicit in animal cruelty on an industrial scale. It is hoped that this paper will contribute to the understanding of the psychological barriers to dietary change; in particular, advocates can identify the stage an individual is at and get a better understanding of the barriers they may face to progress. A better understanding of these individual journeys is likely key to enabling progress to a more ethical food system. 


\section{References}

Abarca, M. E., \& Colby, J. R. (2016). Food memories seasoning the narratives of our lives. Food and Foodways 24(1-2), 1-8.

Alonso, M. E., González-Montaña, J. R., \& Lomillos, J. M. (2020). Consumers' concerns and perceptions of farm animal welfare. Animals, 10(3), 385.

Anderson, J., \& Tyler, L. (2018). Attitudes Toward Farmed Animals in the BRIC Countries. Faunalytics. Available at

Animal Clock. (2020). 2020 UK Animal Kill Clock. Available at www.animalclock.org/uk

Arnaudova, M., Brunner, T. A., \& Götze, F. (2021). Examination of students' willingness to change behaviour regarding meat consumption. Meat Science, 108695.

Asch, S. E. (1951). Effects of group pressure upon the modification and distortion of judgments. Organizational influence processes, 295-303.

Asher, K. \& Green, C. (2016). A Summary of Faunalytics' Study Of Current And Former Vegetarians And Vegans. Faunalytics. Available at https://faunalytics.org/a-summary-offaunalytics-study-of-current-and-former-vegetarians-and-vegans/\#

Attanasio, O., \& Augsburg, B. (2018). Holy cows or cash cows? The economic return to livestock in rural India. Economic Development and Cultural Change, 66(2), 307-330.

Avieli, N. (2013). Grilled nationalism: Power, masculinity and space in Israeli barbeques. Food, Culture \& Society, 16(2), 301-320.

Bastian, B., \& Loughnan, S. (2017). Resolving the meat-paradox: A motivational account of morally troublesome behavior and its maintenance. Personality and Social Psychology Review, 21(3), 278-299.

Baumeister, R. F., \& Vohs, K. D. (2003). Willpower, choice, and self-control.

Blake, C. E., Bell, B. A., Freedman, D. A., Colabianchi, N., \& Liese, A. D. (2013). The eating identity type inventory (EITI). Development and associations with diet. Appetite, 69, $15-22$.

Bolderdijk, J. W., Brouwer, C., \& Cornelissen, G. (2018). When do morally motivated innovators elicit inspiration instead of irritation?. Frontiers in Psychology, 8, 2362.

Bonwick, J. (1894). Irish Druids and old Irish religions. Griffith, Farran. 
Botelho, D., \& Kurtz, H. (2008). The introduction of genetically modified food in the United States and the United Kingdom: A news analysis. The Social Science Journal, 45(1), 13-27.

Boyle, K. J., Desvousges, W. H., Johnson, F. R., Dunford, R. W., \& Hudson, S. P. (1994). An investigation of part-whole biases in contingent-valuation studies. Journal of Environmental Economics and Management, 27(1), 64-83.

Breakwell, G. M. (2014). Identity process theory: clarifications and elaborations. In Identity Process Theory: Identity, social action and social change, 20-37.

Broom, D. M., Sena, H., \& Moynihan, K. L. (2009). Pigs learn what a mirror image represents and use it to obtain information. Animal Behaviour, 78(5), 1037-1041.

Bryant, C. J. (2019a, September 3). A Guide to Effective Animal Campaigning. The Vegan Society. Accessed 03 February 2020 at https://www.vegansociety.com/aboutus/research/research-news/project-update-guide-effective-animal-campaigning

Bryant, C. J. (2019b). We Can't Keep Meating Like This: Attitudes towards Vegetarian and Vegan Diets in the United Kingdom. Sustainability, 11(23), 6844.

Bryant, C., \& Dillard, C. (2019). The impact of framing on acceptance of cultured meat. Frontiers in nutrition, 6, 103.

Buddle, E. A., Bray, H. J., \& Ankeny, R. A. (2018). Why would we believe them? Meat consumers' reactions to online farm animal welfare activism in Australia. Communication Research and Practice, 4(3), 246-260.

Buncombe, A. (2019). The vegetarian town: They wouldn't hurt a fly but the Jains upset Palitana with meat-free plea. The Independent. Available at https://www.independent.co.uk/news/world/asia/the-vegetarian-town-they-wouldn-t-hurt-afly-but-the-jains-upset-palitana-with-meat-free-plea-9588087.html

Camp, B., \& Lawrence, N. S. (2019). Giving pork the chop: Response inhibition training to reduce meat intake. Appetite, $141,104315$.

Campbell, W. K., \& Sedikides, C. (1999). Self-threat magnifies the self-serving bias: A metaanalytic integration. Review of general Psychology, 3(1), 23-43.

Campbell-Arvai, V., Arvai, J., \& Kalof, L. (2014). Motivating sustainable food choices: The role of nudges, value orientation, and information provision. Environment and Behavior, 46(4), 453-475. 
Carfora, V., Caso, D., \& Conner, M. (2017). Correlational study and randomised controlled trial for understanding and changing red meat consumption: The role of eating identities. Social Science \& Medicine, 175, 244-252.

Carruthers, P. (1992). The animals issue: Moral theory in practice. Cambridge: Cambridge University Press.

Carruthers, M. (2000). The craft of thought: Meditation, rhetoric, and the making of images, 400-1200 (Vol. 34). Cambridge: Cambridge University Press.

Caviola, L., Everett, J. A. C., \& Faber, N. S. (2019). The moral standing of animals: Towards a psychology of speciesism. Journal of Personality and Social Psychology, 116(6), 1011.

Chattaraman, V., Lennon, S. J., \& Rudd, N. A. (2010). Social identity salience: Effects on identity-based brand choices of Hispanic consumers. Psychology \& Marketing, 27(3), 263284.

Cialdini, R. B., Demaine, L. J., Sagarin, B. J., Barrett, D. W., Rhoads, K., \& Winter, P. L. (2006). Managing social norms for persuasive impact. Social influence, 1(1), 3-15.

Cole, M., \& Morgan, K. (2011). Vegaphobia: derogatory discourses of veganism and the reproduction of speciesism in UK national newspapers 1. The British Journal of Sociology, 62(1), 134-153.

Cooney, N. (2014a). Diet Change and Demographic Characteristics of Vegans, Vegetarians, Semi-Vegetarians, and Omnivores. Available at http://www.humaneleaguelabs.org/static/reports/2014/04/diet-change-and-demographiccharacteristics1.pdf

Cooney, N. (2014b). Report: What Cover Photos Make People Most Interested In Reading Pro-Veg Literature? Available at http://www.humaneleaguelabs.org/static/reports/2014/08/cover-photos-study-humane-leaguelabs.pdf

Cooney, N. (2014c). Veganomics: The Surprising Science on What Motivates Vegetarians, from the Breakfast Table to the Bedroom. Brooklyn: Lantern Books.

Cornish, A., Raubenheimer, D., \& McGreevy, P. (2016). What we know about the public's level of concern for farm animal welfare in food production in developed countries. Animals, $6(11), 74$.

Corrin, T., \& Papadopoulos, A. (2017). Understanding the attitudes and perceptions of vegetarian and plant-based diets to shape future health promotion programs. Appetite, 109, 40-47. 
Croney, C. C., \& Reynnells, R. D. (2008). The ethics of semantics: Do we clarify or obfuscate reality to influence perceptions of farm animal production?. Poultry science, $87(2)$, 387-391.

Czajkowski, C. (2014). "Dog meat trade in South Korea: A report on the current state of the trade and efforts to eliminate it". Animal Law. 21:29-151.

de Jacourt, L. (1765). Encyclopédie.

Dearing, J., \& Rogers, E. (1988). Agenda-setting research: Where has it been, where is it going. Communication Yearbook, 11(1), 555-594.

Demory-Luce, D., Morales, M., Nicklas, T., Baranowski, T., Zakeri, I., \& Berenson, G. (2004). Changes in food group consumption patterns from childhood to young adulthood: the Bogalusa Heart Study. Journal of the American Dietetic Association, 104(11), 1684-1691.

Devi, S. M., Balachandar, V., Lee, S. I., \& Kim, I. H. (2014). An outline of meat consumption in the Indian population-A pilot review. Korean journal for food science of animal resources, 34(4), 507.

Dhont, K., Hodson, G., Costello, K., \& MacInnis, C. C. (2014). Social dominance orientation connects prejudicial human-human and human-animal relations. Personality and Individual Differences, 61, 105-108.

Dhont, K., Hodson, G., \& Leite, A. C. (2016). Common ideological roots of speciesism and generalized ethnic prejudice: The social dominance human-animal relations model (SDHARM). European Journal of Personality, 30(6), 507-522.

Doebel, S., Gabriel, S., \& Cooney, N. (2015). Report: Is Animal Cruelty, Environmental or Purity ("Abolitionist”) Messaging More Effective At Inspiring People To Change Their Diet? Accessed 19 March 2020 at http://www.humaneleaguelabs.org/static/reports/2015/09/animalcruelty-vs-22abolitionist22-messaging.pdf

Dugan, M., Aldai, N., Aalhus, J., Rolland, D., \& Kramer, J. (2011). Trans-forming beef to provide healthier fatty acid profiles. Canadian Journal of Animal Science, 91(4), 545-556.

Dunbar, N. E., Miller, C. H., Adame, B. J., Elizondo, J., Wilson, S. N., Lane, B. L., ... \& Lee, Y. H. (2014). Implicit and explicit training in the mitigation of cognitive bias through the use of a serious game. Computers in Human Behavior, 37, 307-318.

Eidelman, S., \& Crandall, C. S. (2012). Bias in favor of the status quo. Social and Personality Psychology Compass, 6(3), 270-281. 
Eurobarometer. (2006). Attitudes of EU citizens towards Animal Welfare. European Commission. Accessed 20 March 2020 at https://ec.europa.eu/commfrontoffice/publicopinion/archives/ebs/ebs_270_en.pdf

Faunalytics. (2012). Comparing effectiveness of videos and ads. Accessed 19 March 2020 at https://animalcharityevaluators.org/advocacy-interventions/interventions/onlineads/comparing-effectiveness-of-videos-and-ads/

Fischler, C. (1988). Food, self and identity. Information (International Social Science Council), 27(2), 275-292.

Fotopoulos, C., Krystallis, A., Vassallo, M., \& Pagiaslis, A. (2009). Food Choice Questionnaire (FCQ) revisited. Suggestions for the development of an enhanced general food motivation model. Appetite, 52(1), 199-208.

Funk, A., Sütterlin, B., \& Siegrist, M. (2020). The stereotypes attributed to hosts when they offer an environmentally-friendly vegetarian versus a meat menu. Journal of Cleaner Production, 250, 119508.

Furnham, A. (1993). Just world beliefs in twelve societies. The Journal of social psychology, 133(3), 317-329.

Gallup. (2018, August 1). Snapshot: Few Americans Vegetarian or Vegan. Accessed 17 September 2019 at https://news.gallup.com/poll/238328/snapshot-few-americans-vegetarianvegan.aspx

Gade, D. W. (1976). Horsemeat as human food in France. Ecology of Food and Nutrition, 5(1), 1-11.

Gautam, R., \& Passi, S. (2014). Assessing the Role of Coping Styles as Mediators for Hope and Optimism in Measuring Academic Motivation among First Generation Learners. The International Journal of Indian Psychology, 2(1), 78-93.

Giordano, C. (2019). Yulin Dog Meat Festival: Dogs blow-torched alive in footage from China. The Independent. Available at https://www.independent.co.uk/news/world/asia/yulindog-meat-festival-video-china-blow-torch-animal-cruelty-a8969361.html

Goldstein, N. J., Cialdini, R. B., \& Griskevicius, V. (2008). A room with a viewpoint: Using social norms to motivate environmental conservation in hotels. Journal of consumer Research, 35(3), 472-482.

Gollwitzer, P. M., \& Sheeran, P. (2006). Implementation intentions and goal achievement: A meta-analysis of effects and processes. Advances in experimental social psychology, 38, 69119. 
Grassian, D. T. (2020). The Dietary Behaviors of Participants in UK-Based Meat Reduction and Vegan Campaigns-A Longitudinal, Mixed-Methods Study. Appetite, 154, 104788.

Graça, J., Calheiros, M. M., \& Oliveira, A. (2015). Attached to meat?(Un) Willingness and intentions to adopt a more plant-based diet. Appetite, 95, 113-125.

Griffin, D. R., \& Speck, G. B. (2004). New evidence of animal consciousness. Animal cognition, 7(1), 5-18.

Hall, C. \& Sandilands V. (2007). Public attitudes to the welfare of broiler chickens. Animal Welfare 16, 499-512.

Hansen, P. G., Schilling, M., \& Malthesen, M. S. (2021). Nudging healthy and sustainable food choices: three randomized controlled field experiments using a vegetarian lunch-default as a normative signal. Journal of Public Health, 43(2), 392-397.

Harper, G., \& Henson, S. (2001). Consumer concerns about animal welfare and the impact on food choice. EU FAIR CT98-3678, Centre for Food Economics Research, The University of Reading.

Heleski, C. R., \& Zanella, A. J. (2006). Animal science student attitudes to farm animal welfare. Anthrozoös, 19(1), 3-16.

Herzog, H. (1993). "The Movement Is My Life: The Psychology of Animal Rights Activism”. Journal of Social Issues, 49(1), 103-119.

Herzog, H. (2018, December 04). The Baffling Connection Between Vegetarianism and Depression. Accessed 20 January 2020 at https://www.psychologytoday.com/gb/blog/animals-and-us/201812/the-baffling-connectionbetween-vegetarianism-and-depression

Hielkema, M. H., \& Lund, T. B. (2021). Reducing meat consumption in meat-loving Denmark: Exploring willingness, behavior, barriers and drivers. Food Quality and Preference, 93, 104257.

Hogan, R. (1969). Development of an empathy scale. Journal of consulting and clinical psychology, 33(3), 307.

Hsee, C. K., \& Rottenstreich, Y. (2004). Music, pandas, and muggers: on the affective psychology of value. Journal of Experimental Psychology: General, 133(1), 23. 
Hulshof, R. B. A., Berndt, A., Gerrits, W. J. J., Dijkstra, J., Van Zijderveld, S. M., Newbold, J. R., \& Perdok, H. B. (2012). Dietary nitrate supplementation reduces methane emission in beef cattle fed sugarcane-based diets. Journal of Animal Science, 90(7), 2317-2323.

IPCC. (2018). Global Warming of $1.5^{\circ}$ C: An IPCC Special Report on the Impacts of Global Warming of $1.5^{\circ} \mathrm{C}$ Above Pre-industrial Levels and Related Global Greenhouse Gas Emission Pathways, in the Context of Strengthening the Global Response to the Threat of Climate Change, Sustainable Development, and Efforts to Eradicate Poverty. Intergovernmental Panel on Climate Change.

Ipsos. (2016). Vegan Society Poll. Available at https://www.ipsos.com/ipsos-mori/enuk/vegan-society-poll

Jaspal, R., \& Nerlich, B. (2020). Social representations, identity threat, and coping amid COVID-19. Psychological Trauma: Theory, Research, Practice, and Policy. Advance online publication. http://dx.doi.org/10.1037/tra0000773

Johnson, E. J., Hershey, J., Meszaros, J., \& Kunreuther, H. (1993). Framing, probability distortions, and insurance decisions. Journal of risk and uncertainty, 7(1), 35-51.

Jost, J. T., Banaji, M. R., \& Nosek, B. A. (2004). A decade of system justification theory: Accumulated evidence of conscious and unconscious bolstering of the status quo. Political Psychology, 25(6), 881-919.

Joy, M. (2011). Why we love dogs, eat pigs, and wear cows: An introduction to carnism. Conari press.

Kahneman, D., Knetsch, J. L., \& Thaler, R. H. (1991). Anomalies: The endowment effect, loss aversion, and status quo bias. Journal of Economic perspectives, 5(1), 193-206.

Keller, C., Hartmann, C., \& Siegrist, M. (2016). The association between dispositional selfcontrol and longitudinal changes in eating behaviors, diet quality, and BMI. Psychology \& Health, 31(11), 1311-1327.

Keller, C., \& Siegrist, M. (2015). Does personality influence eating styles and food choices? Direct and indirect effects. Appetite, 84, 128-138.

Klayman, J. (1995). Varieties of confirmation bias. Psychology of Learning and Motivation, $32,385-418$.

Klöckner, C. A., \& Ofstad, S. P. (2017). Tailored information helps people progress towards reducing their beef consumption. Journal of Environmental Psychology, 50, 24-36. 
Knight, A., O'Connell, R., \& Brannen, J. (2014). The temporality of food practices: intergenerational relations, childhood memories and mothers' food practices in working families with young children. Families, Relationships and Societies, 3(2), 303-318.

Kogut, T., \& Ritov, I. (2005). The "identified victim" effect: An identified group, or just a single individual?. Journal of Behavioral Decision Making, 18(3), 157-167.

Krpan, D., \& Houtsma, N. (2020). To veg or not to veg? The impact of framing on vegetarian food choice. Journal of Environmental Psychology, 67, 101391.

Kunda, Z. (1990). The case for motivated reasoning. Psychological Bulletin, 108(3), 480.

Kunst, J. R., \& Hohle, S. M. (2016). Meat eaters by dissociation: How we present, prepare and talk about meat increases willingness to eat meat by reducing empathy and disgust. Appetite, 105, 758-774.

Kurz, T., Prosser, A. M., Rabinovich, A., \& O'Neill, S. (2019). Could Vegans and Lycra Cyclists be Bad for the Planet? Theorizing the Role of Moralized Minority Practice Identities in Processes of Societal-Level Change. Journal of Social Issues.

Lacroix, K., \& Gifford, R. (2019). Reducing meat consumption: Identifying group-specific inhibitors using latent profile analysis. Appetite, 138, 233-241.

Leenaert, T. (2017). How to create a vegan world: A pragmatic approach. New York: Lantern Books.

Lentz, G., Connelly, S., Mirosa, M., \& Jowett, T. (2018). Gauging attitudes and behaviours: Meat consumption and potential reduction. Appetite, 127, 230-241

Lindstorm, E. (2017). The Skeptical Vegan. New York: Skyhorse Publishing.

Loughnan, S., Bastian, B., \& Haslam, N. (2014). The psychology of eating animals. Current Directions in Psychological Science, 23(2), 104-108.

Loughnan, S., Haslam, N., \& Bastian, B. (2010). The role of meat consumption in the denial of moral status and mind to meat animals. Appetite, 55(1), 156-159.

Low, P., Panksepp, J., Reiss, D., Edelman, D., Van Swinderen, B., \& Koch, C. (2012). The Cambridge declaration on consciousness. In Francis Crick Memorial Conference (Vol. 7).

Lowe, D. (2016). Common Arguments for the Moral Acceptability of Eating Meat: A Discussion for Students. Between the Species, 19(1), 7. 
Marks, L. A., Kalaitzandonakes, N. G., Allison, K., \& Zakharova, L. (2003). Media coverage of agrobiotechnology: Did the butterfly have an effect?. Journal of Agribusiness, 21(3452016-15206), 1-20.

Martin, M. J., Thottathil, S. E., \& Newman, T. B. (2015). Antibiotics overuse in animal agriculture: a call to action for health care providers. American Journal of Public Health 105(12), 2409-2410.

McCombs, M. E., \& Shaw, D. L. (1972). The agenda-setting function of mass media. Public Opinion Quarterly, 36(2), 176-187.

McKendree, M. G., Croney, C. C., \& Widmar, N. O. (2014). Effects of demographic factors and information sources on United States consumer perceptions of animal welfare. Journal of Animal Science, 92(7), 3161-3173.

Melendrez-Ruiz, J., Chambaron, S., Buatois, Q., Monnery-Patris, S., \& Arvisenet, G. (2019). A central place for meat, but what about pulses? Studying French consumers' representations of main dish structure, using an indirect approach. Food Research International, 123, 790800.

Melina, V., Craig, W., \& Levin, S. (2016). Position of the Academy of Nutrition and Dietetics: vegetarian diets. Journal of the Academy of Nutrition and Dietetics, 116(12), 19701980.

Mendes, E. (2013). An application of the transtheoretical model to becoming vegan. Social work in public health, 28(2), 142-149.

Mendl, M., Held, S., \& Byrne, R. W. (2010). Pig cognition. Current Biology, 20(18), 796798.

Metcalfe, J., \& Mischel, W. (1999). A hot/cool-system analysis of delay of gratification: dynamics of willpower. Psychological review, 106(1), 3.

Mika, M. (2006). Framing the issue: Religion, secular ethics and the case of animal rights mobilization. Social Forces, 85(2), 915-941.

Minson, J. A., \& Monin, B. (2012). Do-gooder derogation: Disparaging morally motivated minorities to defuse anticipated reproach. Social Psychological and Personality Science, 3(2), 200-207.

Moscovici, S. (1981). On social representations. Social cognition: Perspectives on everyday understanding, 8(12), 181-209. 
Mottus, R., McNeill, G., Jia, X., Craig, L. C., Starr, J. M., \& Deary, I. J. (2013). The associations between personality, diet and body mass index in older people. Health Psychology, 32(4), 353.

Myers, D.G. (2015). Exploring Social Psychology (7th Ed.) New York: McGraw Hill Education.

Nickerson, R. S. (1998). Confirmation bias: A ubiquitous phenomenon in many guises. Review of general psychology, 2(2), 175-220.

Peacock, J. (2018). Measuring Change in Diet for Animal Advocacy. Accessed 19 March 2020 at http://www.humaneleaguelabs.org/static/reports/E009R01-measuring-diet-animaladvocacy.pdf

Piazza, J., \& Loughnan, S. (2016). When meat gets personal, animals' minds matter less: Motivated use of intelligence information in judgments of moral standing. Social Psychological and Personality Science, 7(8), 867-874.

Piazza, J., Ruby, M. B., Loughnan, S., Luong, M., Kulik, J., Watkins, H. M., \& Seigerman, M. (2015). Rationalizing meat consumption. The 4Ns. Appetite, 91, 114-128.

Pohjolainen, P., Vinnari, M., \& Jokinen, P. (2015). Consumers' perceived barriers to following a plant-based diet. British Food Journal.

Poore, J., \& Nemecek, T. (2018). Reducing food's environmental impacts through producers and consumers. Science, 360(6392), 987-992.

Prochaska, J. O., \& DiClemente, C. C. (1983). Stages and processes of self-change of smoking: toward an integrative model of change. Journal of consulting and clinical psychology, 51(3), 390.

Prochaska, J. O., \& Velicer, W. F. (1997). The transtheoretical model of health behavior change. American journal of health promotion, 12(1), 38-48.

Raudenbush, B., \& Frank, R. A. (1999). Assessing food neophobia: The role of stimulus familiarity. Appetite, 32(2), 261-271.

Reese. J. (2017, November 20). Survey of US Attitudes Towards Animal Farming and Animal-Free Food October 2017. Sentience Institute. Accessed 17 September 2019 at https://www.sentienceinstitute.org/animal-farming-attitudes-survey-2017

Reese, J. (2018). The End of Animal Farming: How Scientists, Entrepreneurs, and Activists are Building an Animal-free Food System. Boston: Beacon Press. 
Ritchie, H. \& Roser, M. (2020). Environmental impacts of food production. Our World in Data. Available at https://ourworldindata.org/environmental-impacts-of-food

Rosenfeld, D. L., Rothgerber, H., \& Tomiyama, A. J. (2019). Mostly vegetarian, but flexible about it: investigating how meat-reducers express social identity around their diets. Social Psychological and Personality Science, 1948550619869619.

Roth, S., \& Cohen, L. J. (1986). Approach, avoidance, and coping with stress. American psychologist, 41(7), 813 .

Rothgerber, H. (2013). Real men don't eat (vegetable) quiche: Masculinity and the justification of meat consumption. Psychology of Men \& Masculinity, 14(4), 363.

Rothgerber, H. (2014a). Efforts to overcome vegetarian-induced dissonance among meat eaters. Appetite, 79, 32-41.

Ruby, M. B., \& Heine, S. J. (2011). Meat, morals, and masculinity. Appetite, 56(2), 447-450.

Sachs, A. (2019, November 13). Want to cut down on animal products but just can't give up bacon? Reducetarians won't judge. The Washington Post. Available at https://www.washingtonpost.com/lifestyle/wellness/want-to-cut-down-on-animal-productsbut-just-cant-give-up-bacon-reducetarians-wont-judge/2019/11/11/a51d2b9c-ffee-11e9-8babOfc209e065a8_story.html

Salehi, G., Díaz, E. M., \& Redondo, R. (2020, June). Consumers' reaction to Following Vegan Diet (FVD): An application of Transtheoretical Model (TM) and Precaution Adoption Process Model. In IAPNM 19th conference.

Samuelson, W., \& Zeckhauser, R. (1988). Status quo bias in decision making. Journal of Risk and Uncertainty, 1(1), 7-59.

Schenk, P., Rössel, J., \& Scholz, M. (2018). Motivations and constraints of meat avoidance. Sustainability, 10(11), 3858.

Seger, C. A., \& Spiering, B. J. (2011). A critical review of habit learning and the basal ganglia. Frontiers in systems neuroscience, 5, 66.

Shepperd, J., Malone, W., \& Sweeny, K. (2008). Exploring causes of the self-serving bias. Social and Personality Psychology Compass, 2(2), 895-908.

Signicom (1997). Dierenwelzijn in de bio-industrie [Animal welfare in the organic industry]. Signicom: Amsterdam.

Singer, P. (1975). Animal Liberation. New York: New York Review. 
Slovic, Paul (2007). "If I look at the mass I will never act": Psychic numbing and genocide. Judgment and Decision Making. 2: 79-95.

Smith, K. S., \& Graybiel, A. M. (2013). A dual operator view of habitual behavior reflecting cortical and striatal dynamics. Neuron, 79(2), 361-374.

Thaler, R. (2009, September 26). Opting in vs. Opting Out. The New York Times. Accessed 20 March 2020 at https://www.nytimes.com/2009/09/27/business/economy/27view.html

Tomasik, B. (2018). How Much Direct Suffering is Caused By Various Animal Foods? Accessed 20 September 2019 at https://reducing-suffering.org/how-much-direct-suffering-iscaused-by-various-animal-foods/

Twenge, J. M., Zhang, L., \& Im, C. (2004). It's beyond my control: A cross-temporal metaanalysis of increasing externality in locus of control, 1960-2002. Personality and Social Psychology Review, 8(3), 308-319.

Van Der Weele, C., \& Driessen, C. (2019). How normal meat becomes stranger as cultured meat becomes more normal; Ambivalence and ambiguity below the surface of behavior. Frontiers in Sustainable Food Systems, 3, 69.

Vegan Outreach. (2016). Booklet Comparison Study. Accessed 19 March 2020 at https://veganoutreach.org/ppr-2016/

Verbeke, W. (2009). Stakeholder, citizen and consumer interests in farm animal welfare. Animal Welfare, 18(4), 325-333.

Verbeke, W., Pieniak, Z., Brunso, K., Scholderer, J., \& Olsen, S. O. (2008). Evaluating consumer information needs in the purchase of seafood products. In: Børresen T (ed) Improving Seafood Products for the Consumer pp 63-84. Woodhead Publishing Limited: Cambridge, UK.

Verbeke, W., \& Ward, R. W. (2006). Consumer interest in information cues denoting quality, traceability and origin: An application of ordered probit models to beef labels. Food quality and preference, 17(6), 453-467.

Verplanken, B., Roy, D., \& Whitmarsh, L. (2018). Cracks in the wall: Habit discontinuities as vehicles for behaviour change. In The Psychology of habit (pp. 189-205). Springer, Cham.

Vignoles, V. L., Chryssochoou, X., \& Breakwell, G. M. (2002). Evaluating models of identity motivation: Self-esteem is not the whole story. Self and Identity, 1(3), 201-218. 
Willett, W., Rockström, J., Loken, B., Springmann, M., Lang, T., Vermeulen, S., ... \& Jonell, M. (2019). Food in the Anthropocene: the EAT-Lancet Commission on healthy diets from sustainable food systems. The Lancet, 393(10170), 447-492.

Wolstenholme, E., Carfora, V., Catellani, P., Poortinga, W., \& Whitmarsh, L. (2021).

Explaining intention to reduce red and processed meat in the UK and Italy using the theory of planned behaviour, meat-eater identity, and the Transtheoretical model. Appetite, 105467.

Wood, W., Labrecque, J. S., Lin, P. Y., \& Rünger, D. (2014). Habits in dual process models. Dual process theories of the social mind, 371-385. 